\title{
Layout Optimization of Rail Expansion Joint on Long-Span Cable-Stayed Bridge for High-Speed Railway
}

\author{
Xiaopei Cai, ${ }^{1}$ Wanli Liu, ${ }^{1}$ Kaize Xie, ${ }^{2}$ Wenjun Zhu $\mathbb{D},{ }^{3}$ Xiyuan Tan, ${ }^{1}$ and Yongjie Gao ${ }^{4}$ \\ ${ }^{1}$ School of Civil Engineering, Beijing Jiaotong University, Beijing 100044, China \\ ${ }^{2}$ Structural Health Monitoring and Control Institute, Shijiazhuang Tiedao University, Shijiazhuang 050043, China \\ ${ }^{3}$ Shanghai Key Laboratory of Rail Infrastructure Durability and System Safety, College of Transportation Engineering, \\ Tongji University, Shanghai 201804, China \\ ${ }^{4}$ China Railway Siyuan Survey and Design Group Co., Ltd., Wuhan 430000, China
}

Correspondence should be addressed to Wenjun Zhu; xxdhzwj@gmail.com

Received 28 April 2020; Revised 1 July 2020; Accepted 2 July 2020; Published 27 July 2020

Academic Editor: Qiang Tang

Copyright (c) 2020 Xiaopei Cai et al. This is an open access article distributed under the Creative Commons Attribution License, which permits unrestricted use, distribution, and reproduction in any medium, provided the original work is properly cited.

Continuous welded rail (CWR) has been widely applied to the Chinese high-speed railways. It is interesting to reduce the effect of rail longitudinal force on the long-span cable-stayed bridges. Taking the pile-soil interaction into account, the finite element model of CWR on the long-span cable-stayed bridge is established based on the bridge-track interaction theory. The rail longitudinal force can be reduced and the track stability can be improved significantly by installing Rail Expansion Joint (REJ). The layout scheme of REJ plays a controlling role on designing CWR on bridges. Results show that the unidirectional REJ should be laid on both ends of the long-span cable-stayed bridge. Switch rails of REJ are set up on the main beam, stock rails are laid on the simply supported beams and crossing over beam joints, and several-meter long small resistance fasteners need to be laid on the sides of stock rails to reduce the fixed pier longitudinal force near the main beam. The range of REJ laid on cable-stayed bridge is mainly determined by temperature, rail breaking, and seismic condition; the bending and braking loads have little influence on it. Multiple field tests are carried out to prove the validity of the numerical model and the design methodology.

\section{Introduction}

As a kind of cable system, cable-stayed bridge has been widely applied in high-speed railway construction due to its large spanning capability. The bridge-track interactionis aggravated under the effects of various loads including the temperature, train load, and seismic load [1-8]. The bridgetrack interaction and distribution of rail longitudinal force on the long-span bridges are more complex than those on simply supported bridges and concrete continuous bridges $[9,10]$.

The track and cable-stayed bridge are investigated in different aspects, including the exploration of nonlinear finite element model (FEM) of cable-stayed bridges [11], nonlinear analysis program [12], nonlinear static analysis of cable structures [13], the influence of distinct parameters on the mechanical properties of track on long-span cable-stayed bridges by FEM [14], experimental tuning of the model [15], the distribution of rail longitudinal force including expansion force, and braking force on the cable-stayed bridges [16-20]. The simulation process and design of CWR on cable-stayed bridges are simplified [21]. As a result, the optimal layout of CWR is relatively scarce.

The Rail Expansion Joint (REJ) is a necessary device on long-span bridges, which can alleviate the bridge-track interaction decreasing the rail longitudinal force. Some researches about REJ have been carried out. Xie et al. studied the dynamic response of REJs located at continuous beam bridge under the earthquake [22]. Min et al. adjusted REJ by measuring the installation location to improve the maintenance efficiency and reduce the cost [23]. Bae et al. analyzed the longitudinal displacement of the sleepers in REJ zone by simulating the ballast track with beam and spring elements [24]. Chung and Lee analyzed the longitudinal force of REJs 
on bridge under temperature load [25]. In the previous studies, the influence of REJ installation was investigated, but the layout of REJ in influencing the rail and piers longitudinal force is ignored. A reasonable layout of REJ can reduce the rail and pier longitudinal force simultaneously and improve the operating state of railways. However, the research on REJ layout of cable-stayed bridges is still limited. The optimization methods are not unified [26].

This research will mainly take a cable-stayed bridge with laying CWR under construction in China as a case; the influence of REJ on the rail and piers longitudinal force is investigated. An optimization method for choosing the installation location of REJ on the cable-stayed bridge is put forward. The field monitoring data of the existing cable-stayed bridge are compared with the simulation results of the new bridge to verify the optimal scheme. The conclusions will be helpful for the layout optimization method of REJ on the cable-stayed bridges.

\section{Calculation Theory and Model}

2.1. Calculation Theory. The calculation method of rail longitudinal force is established based on the bridge-track interaction theory. The derivation of bridge-track interaction theory is based on equilibrium condition of rail microelement as shown in Figure 1. $u_{r(x)}$ denotes the rail longitudinal displacement and $u_{b(x)}$ refers to the longitudinal displacement of the upper surface of the bridge; both $u_{r(x)}$ and $u_{b(x)}$ are positive to the right; the beam-rail relative displacement is $u$ and is shown in the following formula:

$$
u=u_{r(x)}-u_{b(x)} .
$$

Consider a part of rail with an infinitesimal length of $d x$ in Figure 1. $P$ is the rail axial force (take tension as positive); $r(u)$ is the gradient of longitudinal resistance. According to the longitudinal balance principle of infinitesimal rail, the following formula can be deduced:

$$
P+r(u) d x=P+d P \text {. }
$$

By changing formulae (2), the following (3) can be derived:

$$
\frac{d P}{d x}=r(u)
$$

Considering rail material as linear elastic material, according to the geometric equation and physical equation of elasticity mechanics, the following formulae can be derived:

$$
\begin{aligned}
& \varepsilon=\frac{d u_{r}}{d x}, \\
& \varepsilon=\frac{\sigma}{E}=\frac{P}{(E F)},
\end{aligned}
$$

where $\varepsilon$ is the rail strain. $\sigma$ is the rail stress; $E$ is the elastic modulus of rail; $F$ is the cross-sectional area of rail.

Substituting formulae (5) into (4), the following formula can be derived:

$$
P=E F \times \frac{d u_{r}}{d x}
$$

Substituting formulae (6) into (3), the following formula can be obtained:

$$
E F \times \frac{d^{2} u_{r}}{d x^{2}}=r(u) .
$$

Substituting formula (1) into formulae (7), the following can be derived:

$$
\begin{aligned}
& \frac{d^{2} u_{r}}{d x^{2}}=\frac{r(u)}{E F}, \\
& \frac{d^{2} u}{d x^{2}}=\frac{r(u)}{E F}-\frac{d^{2} u_{b}}{d x^{2}} .
\end{aligned}
$$

Formula (9) is the differential equation of bridge-track interaction.

According to the rail geometric boundary condition that there is no displacement of rail in the rail fixed area. The following formula is

$$
\int d u_{r}=\int \frac{x P d x}{E F}=0
$$

Once the description form of $r(u)$ is determined, the rail longitudinal displacement and rail longitudinal force can be solved by formulae (8)-(10). Due to the complicated interaction between the cable-stayed bridge and CWR system, formulae (8)-(10) are too difficult to solve, so the finite element method is used to analyze CWR on the cable-stayed bridge.

2.2. Railway Track on the Cable-Stayed Bridge. A cable-stayed bridge under construction in China is modeled in this investigation, with four-line high-speed railway on it. The main beam is steel-concrete composite box beam with six spans of $50+274+672+224+50+50 \mathrm{~m}$. The type of track on bridge is ballast track. The existing models for analyzing bridge-track interaction of CWR on cable-stayed bridges are two dimensional models, in which the factors include influence of multiline of rail, mechanical behavior of cable-stayed bridges, and geometric nonlinearity which are ignored. Thus, a trackbeam-cable-tower spatial model for analyzing bridge-track interaction of CWR on cable-stayed bridge is established. The approach spans at left and right sides of cable-stayed bridge are simplified as $5 \times 48 \mathrm{~m}$ and $5 \times 32 \mathrm{~m}$, simply-supported concrete beam bridges, respectively, which are shown in Figure 2(a).

2.2.1. Ballast Track Model. The track comprises $60 \mathrm{~kg} / \mathrm{m}$ rail, type III concrete sleepers, elastic bar II-type fasteners, and small resistance fasteners. The rail is connected to the sleepers by fasteners; sleepers are connected to the main beam of bridge by ballast bed; the Timoshenko beam element is adopted for the simulation of the rail so as to take the shear deformation into account. In order to reduce the impact of boundary conditions on the calculated results, both sides of rail are extended for $100 \mathrm{~m}$ out of the bridges; two ends of rail are fixed. Sleepers are divided into beam elements by supporting point of rail; the fasteners and ballast bed elements are modeled by three-dimensional spring system. One end of a fastener spring connects with a rail node and the other end connects with a sleeper node. The 


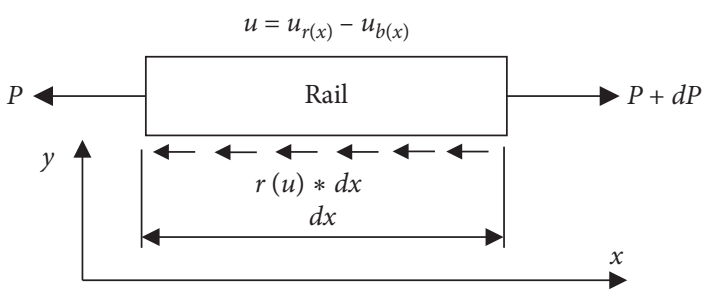

Figure 1: Longitudinal balance of infinitesimal rail.

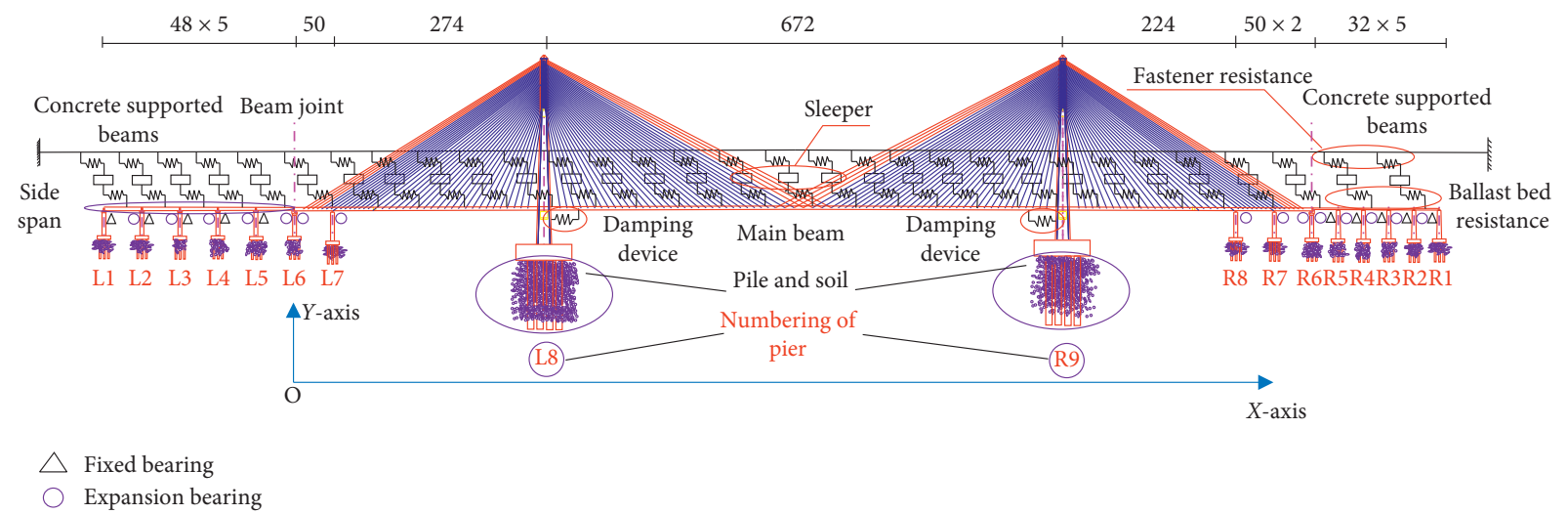

(a)

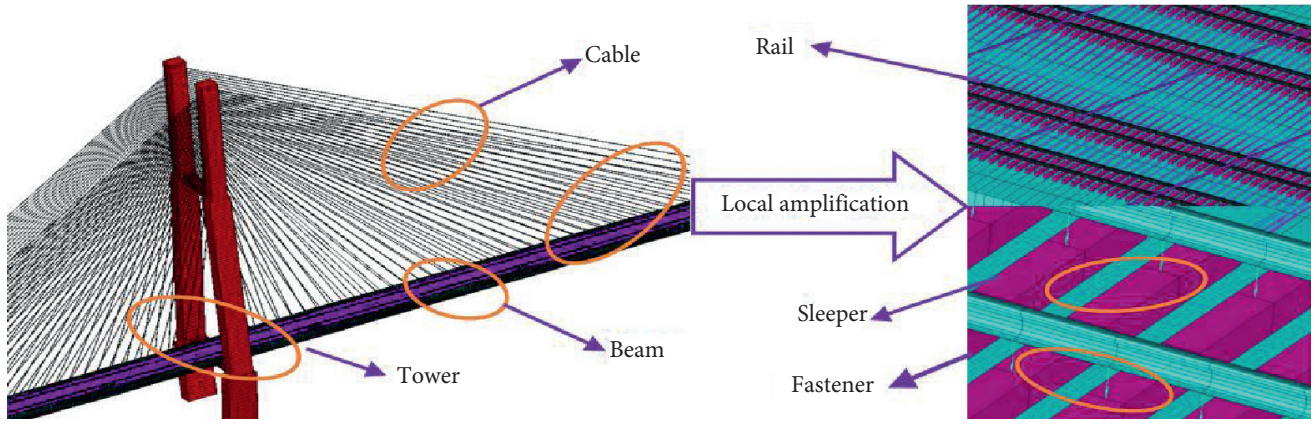

(b)

Figure 2: Track-beam-cable-tower spatial model. (a) Global image of the track-bridge (unit: m). (b) Bridge and track system.

two ends of the ballast bed spring connect to the sleeper node and the main beam node, respectively. The longitudinal and transverse resistance of fasteners and ballast bed are simulated as nonlinear spring elements. The vertical constraints of that are modeled by linear spring elements.

2.2.2. Cable-Stayed Bridge Model. The cable-stayed bridge is a separate tower-beam and consolidated tower-pier form that is composed of beams, stay cables, and double towers. The H-typed main towers are constructed by reinforced concrete with heights of $252 \mathrm{~m}$ and $242 \mathrm{~m}$, respectively. 304 stay cables are fabricated by 8 kinds of parallel wire bundles. The damping devices are used to connect towers with main beam. The geometric nonlinearity of cable-stayed bridge is considered. The stay cables subjecting to the axial force are simulated by the link elements; the impact of stay cable sag effect on bridge-track interaction is so little that can be ignored [27]. Three-dimensional beam elements are applied to simulate the main towers, main beam, and piers by taking into account the bearing axial force and bending moment. The damping devices are modeled by spring elements and only used when trains brake and accelerate. The fixed bearings of the simply supported beam approach bridges on each side are set apart from the cable-stayed bridge. The beams, piers, and abutments of approach bridges are simulated as beam elements. The beams and piers are tied on horizontal and vertical direction at fixed bearings, while the bridge has longitudinal freedom at expansion bearings. The bottom of the main towers and piers is piles and soil.

2.2.3. Pile-Soil Interaction Model. Pile-soil interaction is a difficult problem in seismic research of bridges. Spring elements are used to simulate the interaction of pile-soil structure. The piles are modeled as beam elements laid on elastic foundation. According to the soil conditions and the mechanism of pile-soil interaction, the soil around piles is simplified as equivalent soil 
spring elements according to the equal stiffness principle when calculating the horizontal resistance of piles. The method assumes that the soil is linear elastic continuous medium, and the equivalent spring stiffness is calculated by "m-method." The calculation method is as shown as

$$
\sigma_{z x}=m \cdot z \cdot x_{z}
$$

where $\sigma_{z x}$ is the lateral resistance that the soil acts to pile; $m$ is foundation coefficient which can be got from the code [28]; $z$ is the depth of soil layer; $x_{z}$ is the pile lateral displacement at the depth of $z$.

From the definition of stiffness of soil spring element, the following formula can be derived:

$$
K_{S}=\frac{A \cdot \sigma_{z x}}{x_{z}}
$$

where $K_{S}$ is the stiffness of soil spring element and $A$ is the contact area between pile and soil.

Substituting formulae (11) into (12), the following formula can be derived as

$$
K_{s}=\frac{\left(a \cdot b_{P}\right)\left(m \cdot z_{x} \sigma_{z}\right)}{x_{z}}=a \cdot b_{P} \cdot m \cdot z,
$$

where $a$ is the thickness of the soil layer and $b_{P}$ is the width of the soil layer in the direction perpendicular to the plane where the calculation model is located.

2.3. Parameters and Loads. All track parameters are obtained from the actual situations and code [29]. The longitudinal resistance-displacement diagrams of constant resistance fastener, small resistance fastener, and ballast bed are shown in Figure 3. The parameters of bridges are got from China Railway Siyuan Survey and Design Group C. Table 1 shows the parameters of the bridge, towers, stay cables, and rail. The height and vertical moment of inertia of $48 \mathrm{~m}$ simply supported beam section are $3.2 \mathrm{~m}$ and $11.81 \mathrm{~m}^{4}$, and those for $32 \mathrm{~m}$ simply supported beam are $2.6 \mathrm{~m}$ and $10.24 \mathrm{~m}^{4}$. The longitudinal stiffness of abutments and piers of approach bridges is $1.2 \times 10^{5} \mathrm{kN} / \mathrm{m}$ and $6 \times 10^{4} \mathrm{kN} / \mathrm{m}$, respectively. The pile is drilling pile, the diameter of pile laid on the bottle of approach bridges is $1.5 \mathrm{~m}$, and that for main span and towers is $2.5 \mathrm{~m}$. The longitudinal stiffness of damping devices is $200 \mathrm{kN} / \mathrm{m}$ under braking condition [30].

When calculating rail expansion force, the temperature differential amplitudes of steel beam and stay cables on the ballast bed are $25^{\circ} \mathrm{C}$, and those for concrete beams and main towers are $15^{\circ} \mathrm{C}$. The highest and the lowest rail temperatures are $61.9^{\circ} \mathrm{C}$ and $-27.4^{\circ} \mathrm{C}$, respectively. The maximum rising and dropping temperature differentials of rail are $41.9^{\circ} \mathrm{C}$ and $53.4^{\circ} \mathrm{C}$, respectively. The vehicle type is $\mathrm{CRH} 3$ train, the axle load of the train is $17 \mathrm{t}$, the length of the wheelbase is $2.5 \mathrm{~m}$, and the dynamic bending stress caused by the train at the rail head (bottom) is $149.40 \mathrm{MPa}(128.04 \mathrm{MPa})$. The ZK standard live load as shown in Figure 4 is applied to the track. The adhesion coefficient between wheel and rail is 0.164 . The length of bending and braking loads is $400 \mathrm{~m}[29,31]$.

\section{Designing of CWR}

CWR on bridges should meet the requirements of rail strength and track stability to ensure the running safety of train.

Though REJ can coordinate the longitudinal deformation of bridge and CWR and release rail longitudinal force automatically, its structural characteristics make it the weak region of the track structure; REJ should be avoided as much as possible. When designing CWR on cable-stayed bridges, it is better to evaluate constant resistance fasteners without REJ according to the requirement. If it is not satisfied, the small resistance fasteners will be preferred. When that two schemes cannot satisfy the requirements, REJ needs to be used. The layout and quantity of REJ need to be determined reasonably according to the engineering practice.

3.1. Control and Contrast Index. For the design and checkcalculation of CWR, the codes formulated by various countries and organizations are different. China has built the longest high-speed railway in the world; the design and calculation technology of CWR are mature. Thus, codes for designing CWR [29] made by China railway organization are used as structural calculation rules. CWR should definitely meet the requirements of the rail strength and the track stability.

3.1.1. Rail Strength. To meet the requirement of rail strength, the compressive stress at the rail head and tensile stress at the rail bottom shall not be greater than the permissible stress of $351.50 \mathrm{MPa}$. According to literature research $[29,32]$, the calculation result of rail longitudinal stress tends to be conservative through routine linear superposition method which has been adopted in code. The code formulated of rail longitudinal stress can be calculated with the following formula:

$$
\sigma_{d}+\sigma_{t}+\sigma_{f}+\sigma_{z} \leq[\sigma]=\frac{\sigma_{s}}{K}
$$

where $\sigma_{d}$ is dynamic bending stress at the rail head and bottom; $\sigma_{t}$ is rail basic thermal stress; $\sigma_{f}$ is rail additional stress, which is larger one of rail expansion stress and rail bending stress; and $\sigma_{z}$ is rail braking stress; $[\sigma]$ is permissible stress of rail; $\sigma_{s}$ is yield strength of rail $(457 \mathrm{MPa})$; and $K$ is the safety factor (1.3).

3.1.2. Track Stability. Many research programs are conducted on the stability of CWR all over the world [33-35]. The stability of CWR on the ballast bed is calculated by a "unified formula" according to the code [29]. The permissible force is $1505.10 \mathrm{kN}$. In order to keep the stability of ballast bed, the beam-rail relative displacement under braking load is no more than $4 \mathrm{~mm}$ when constant resistance fasteners are used and that cannot be beyond $30 \mathrm{~mm}$ when small resistance fasteners are applied. 


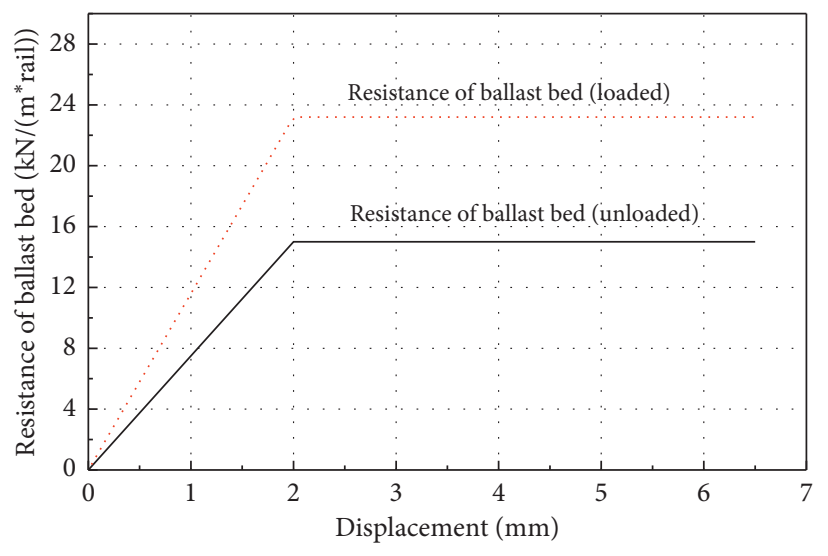

(a)

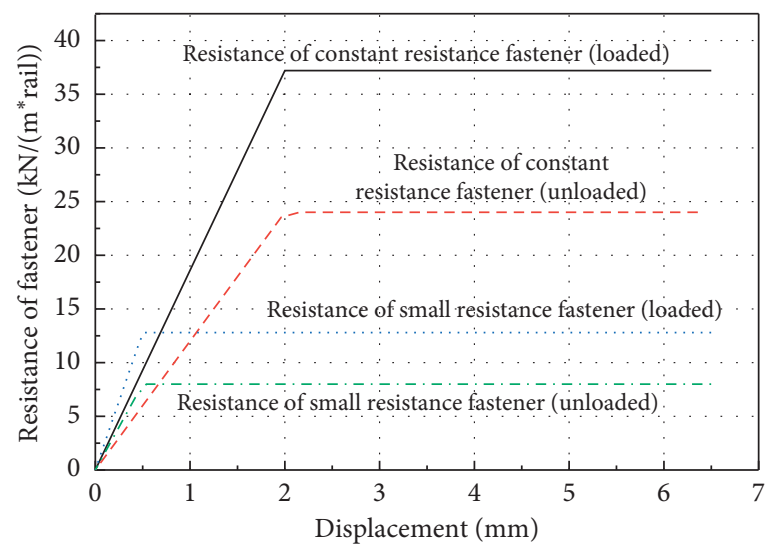

(b)

FIgURE 3: Longitudinal resistance-displacement diagram. (a) Ballast bed. (b) Fastener.

TABLE 1: Main parameters.

\begin{tabular}{|c|c|c|c|c|}
\hline Structure & Items & Units & Simply supported beam & Steel box beam \\
\hline \multirow{4}{*}{ Beam } & Modulus of elasticity & $\mathrm{N} / \mathrm{m}^{2}$ & $3.6 \times 10^{10}$ & $2.1 \times 10^{11}$ \\
\hline & Poisson ratio & - & 0.2 & 0.3 \\
\hline & Coefficient of thermal expansion & $/{ }^{\circ} \mathrm{C}$ & $1.0 \times 10^{-5}$ & $1.2 \times 10^{-5}$ \\
\hline & Density & $\mathrm{kg} / \mathrm{m}^{3}$ & 2625 & 7875 \\
\hline \multirow{4}{*}{ Main tower } & Modulus of elasticity & $\mathrm{N} / \mathrm{m}^{2}$ & \multicolumn{2}{|c|}{$3.6 \times 10^{10}$} \\
\hline & Poisson ratio & - & \multicolumn{2}{|c|}{0.2} \\
\hline & Coefficient of thermal expansion & $/{ }^{\circ} \mathrm{C}$ & \multicolumn{2}{|c|}{$1 \times 10^{-5}$} \\
\hline & Density & $\mathrm{kg} / \mathrm{m}^{3}$ & \multicolumn{2}{|c|}{2625} \\
\hline \multirow{4}{*}{ Stay cable } & Elastic modulus of stay cable material & $\mathrm{N} / \mathrm{m}^{2}$ & \multicolumn{2}{|c|}{$1.98 \times 10^{11}$} \\
\hline & Cross-sectional area & $\mathrm{m}^{2}$ & \multicolumn{2}{|c|}{$1.16 \times 10^{-2}$} \\
\hline & Poisson ratio & - & \multicolumn{2}{|c|}{0.3} \\
\hline & Coefficient of thermal expansion & $/^{\circ} \mathrm{C}$ & \multicolumn{2}{|c|}{$1.2 \times 10^{-5}$} \\
\hline \multirow{5}{*}{ Rail CHN60 } & Modulus of elasticity & $\mathrm{Pa}$ & \multicolumn{2}{|c|}{$2.06 \times 10^{11}$} \\
\hline & Cross-sectional area & $\mathrm{m}^{2}$ & \multicolumn{2}{|c|}{$7.745 \times 10^{-3}$} \\
\hline & Poisson ratio & - & \multicolumn{2}{|c|}{0.3} \\
\hline & Coefficient of thermal expansion & $/{ }^{\circ} \mathrm{C}$ & \multicolumn{2}{|c|}{$1.18 \times 10^{-5}$} \\
\hline & Density & $\mathrm{kg} / \mathrm{m}^{3}$ & \multicolumn{2}{|c|}{7850} \\
\hline
\end{tabular}

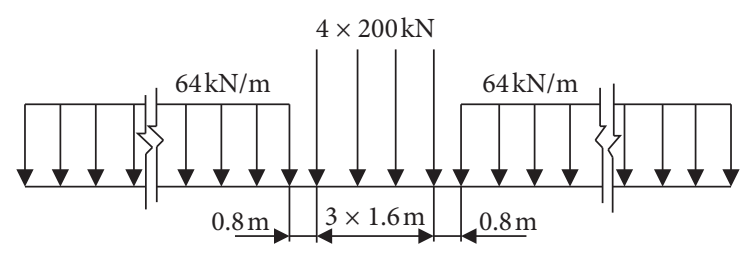

FIgURE 4: ZK standard live load.

3.2. Initial Layout of REJ. When designing CWR on longspan cable-stayed bridges, the schemes that constant resistance fasteners or small resistance fasteners are laid on the whole bridge should be adopted at first.

The rail temperature dropping amplitude is greater than that of temperature rising. The temperature dropping condition is considered as the most unfavorable condition in this investigation. The temperature of steel beam and stay cables reduces by $25^{\circ} \mathrm{C}$, that for the concrete beams and the main towers is $15^{\circ} \mathrm{C}$, and the rail temperature reduces to $53.4^{\circ} \mathrm{C}$. Figure 5 shows rail longitudinal force when the main beam and the concrete supported beams are paved with the constant or small resistance fasteners. Under temperature dropping condition (Figure 5(a)), the amplitudes of rail longitudinal force are $2623.20 \mathrm{kN}$ and $2202.70 \mathrm{kN}$ corresponding to the constant and small resistance fasteners, respectively. It can be concluded that small resistance fastener is of great benefit for reducing rail expansion force. At the main beam joint, the additional force reaches maximum owing to the maximum expansion amounts of main beam.

Figure 5(b) illustrates rail longitudinal force when ZK load is applied to the middle span and rail temperature drops. Similarly, the maximum forces are $1489.40 \mathrm{kN}$ and $1433.90 \mathrm{kN}$ at main beam joints, respectively. Figure 5(c) shows the distribution of rail braking force when four-line braking loads act within $400 \mathrm{~m}$ on the right side of beam joint. It can be known that when constant resistance fasteners and small resistance fasteners are laid, respectively, the maximum extensile forces are $486.73 \mathrm{kN}$ and $451.24 \mathrm{kN}$ at the left beam joint of the main beam, the 


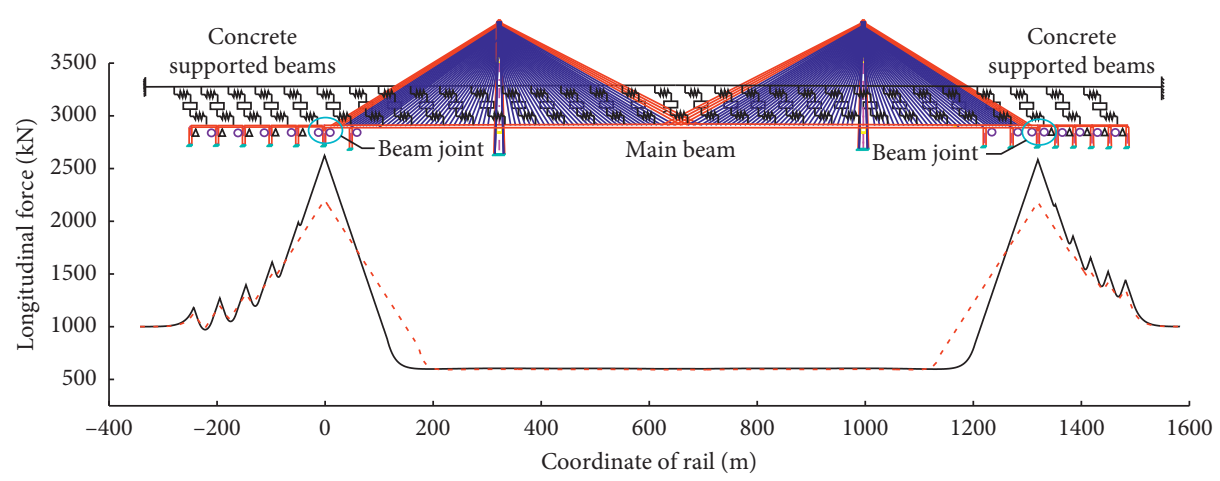

$\triangle$ Fixed bearing
$\bigcirc$ Expansion bearing

- Constant resistance fasteners

_ - - Small resistance fasteners

(a)

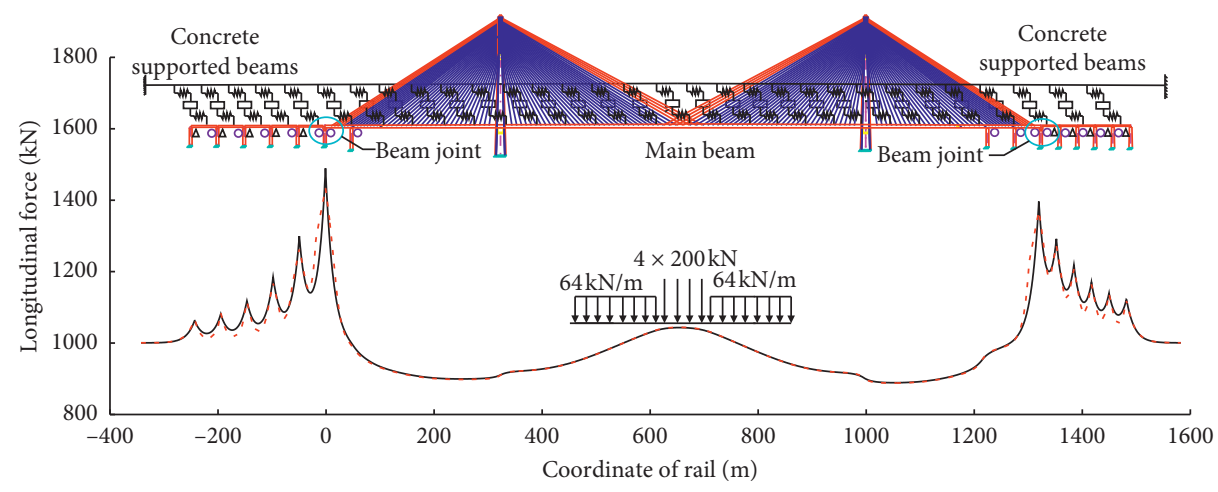

$\triangle$ Fixed bearing

$\bigcirc$ Expansion bearing

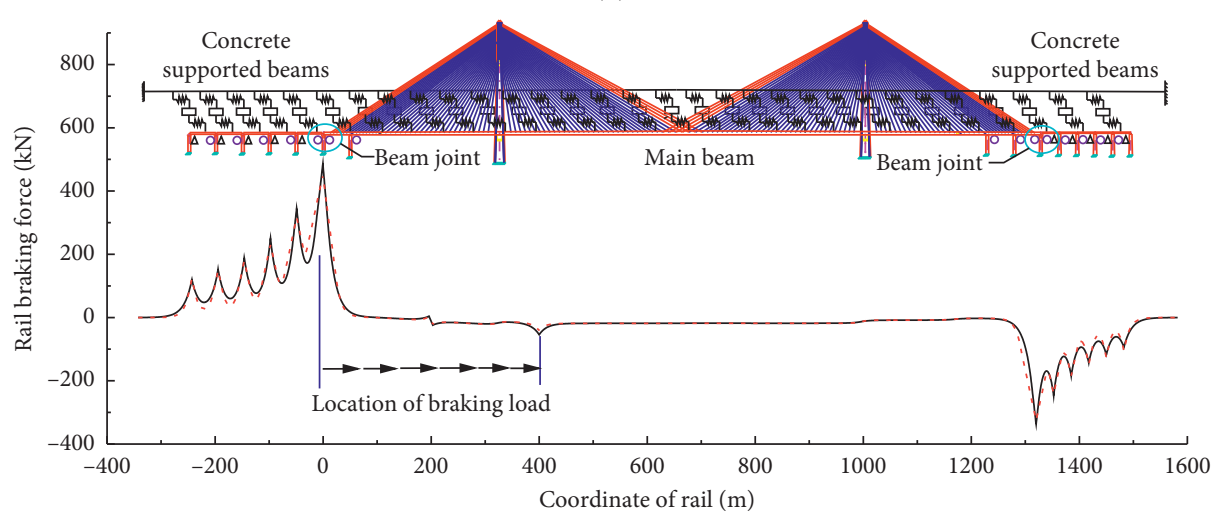

$\triangle$ Fixed bearing

$\bigcirc$ Expansion bearing
_- Constant resistance fasteners

_ - - Small resistance fasteners

(b)

$$
\begin{aligned}
& \text { _ Constant resistance fasteners } \\
& \text { - - Small resistance fasteners }
\end{aligned}
$$

(c)

FIgURE 5: Rail longitudinal force. (a) Longitudinal force under temperature drop condition. (b) Longitudinal force under bending condition. (c) Longitudinal force under braking condition.

maximum compressive forces are $337.20 \mathrm{kN}$ and $325.91 \mathrm{kN}$ at the right beam joint of main beam, and the force at the middle span of bridge is almost zero. It can be concluded that laying small resistance fasteners can reduce the braking force but little.

It can be concluded from Figure 5 that the maximum rail longitudinal force appears at the main beam joints under temperature dropping, bending, and braking condition. The amplitude of rail longitudinal force under bending condition is much smaller than that under temperature dropping condition, so rail longitudinal force under temperature load is considered in the design of CWR.

Dynamic bending stress at the rail head and bottom, the basic thermal stress, expansion additional stress, and braking stress are selected to check rail strength. Table 2 shows that rail effective stress is greater than the requirement. 
TABLE 2: Rail strength calculation (unit: MPa).

\begin{tabular}{lcccccrrr}
\hline \multirow{2}{*}{ Item } & \multirow{2}{*}{$\sigma_{d}$} & \multicolumn{2}{c}{$\sigma_{t}+\sigma_{f}$} & \multicolumn{2}{c}{$\sigma_{z}$} & \multicolumn{2}{c}{$\sum \sigma$} & \\
& & Constant & Small & Constant & Small & Constant & Small & {$[\sigma]$} \\
\hline Compressive stress of head & 149.40 & 311.27 & 256.44 & 62.84 & 58.26 & 523.51 & 464.10 & 351.50 \\
Tensile stress of rail bottom & 128.04 & 338.70 & 284.40 & 62.84 & 58.26 & 529.58 & 470.70 & 351.50 \\
\hline
\end{tabular}

Superposing rail basic thermal force and rail expansion force is to evaluate the stability of CWR with constant and small resistance fasteners. The amplitudes of rail longitudinal force are $2402.40 \mathrm{kN}$ and $1981.90 \mathrm{kN}$ under temperature rising condition, much larger than the permissible force of $1505.10 \mathrm{kN}$, which unsatisfied the requirements of track stability.

The main beams of cable-stayed bridges are longer; the force and deformation of CWR laid on the bridge are larger than common continuous bridges. The rail strength and track stability on the stayed-cable bridge are not able to satisfy the requirement stipulated in the code [29] without REJ according to the numerical simulation. So REJ should be used on the bridge. Two kinds of REJ laying schemes are proposed. Two sets of unidirectional REJ are arranged at the main beam ends as shown in Figure 6.

According to practical engineering experience, switch rails are fixed with constant fasteners while stock rails expand, and small resistance fasteners should at least cover the stock rail expansion zones of rails. For scheme 1, switch rails are located at the main beam; stock rails are set up on the simply supported beams and cross over beam joints. For scheme 2, switch rails are located at the simply supported beams; stock rails are set up on the main beam and cross over beam joints.

\section{Optimization of REJ Layout}

The feasibility of the two REJ laying schemes needs to be determined by rail strength and track stability.

4.1. Rail Longitudinal Force with REJs. The temperature of the cable-stayed bridge components and rail drops and rises, respectively. Figure 7 (a) shows the rail longitudinal force with variation of temperature (expansion condition). The amplitudes of rail longitudinal force are $1023.79 \mathrm{kN}$ and $803.32 \mathrm{kN}$ at both ends of rail, which is considered as rail basic thermal forces. The maximum rail longitudinal forces on the main bridge are $770.17 \mathrm{kN}$ and $552.66 \mathrm{kN}$. It can be known from Figure 7 that rail longitudinal force of the section laying small resistance fasteners is smaller than that of section laying constant resistance fasteners. But the effect of small resistance fasteners on reducing the peak value of rail longitudinal force is not obvious.

The most unfavorable bending condition can be determined by changing the position of train load. Figure 8 shows rail longitudinal force under rail temperature variation and bending loads (bending condition). The maximum rail tensile force is $1015.02 \mathrm{kN}$ at the mid-span of the main beam when four-line ZK-train loads apply from left tower to $724 \mathrm{~m}$ zone and rail temperature reduces to $53.4^{\circ} \mathrm{C}$. Four-line
ZK-train loads apply from $564 \mathrm{~m}$ to $964 \mathrm{~m}$ zone and rail temperature increases by $41.9^{\circ} \mathrm{C}$; the maximum compressive force is $964.70 \mathrm{kN}$, locating at the position that is $235 \mathrm{~m}$ away from the right main beam joint. The amplitudes of rail longitudinal force under bending condition are larger than those under expansion condition after laying REJs, so rail longitudinal force under bending condition is taken to deduce rail strength and track stability.

Four-line braking loads are applied from $660 \mathrm{~m}$ to $1060 \mathrm{~m}$ (case 1) and the section is from $1085 \mathrm{~m}$ to $1485 \mathrm{~m}$ (case 2); CWR on main beam is under the most unfavorable condition with superposition of thermal force, bending, and braking force. Because small resistance fasteners have little influence on rail braking force, only scheme 1 is considered under braking condition. Figure 9(a) shows rail longitudinal force under braking conditions. The maximum rail tensile force under case 1 is $56.24 \mathrm{kN}$ on the left end of loading section. In case 2 , the maximum compressive force is $63.34 \mathrm{kN}$ on the left end of loading section. Figure 9(b) shows the beam-rail relative displacement. Under case 1 , the peak value of relative displacement is $0.83 \mathrm{~mm}$ on the middle of loading section; the beam-rail relative displacement distributes about the loading of mid-span antisymmetric. For case 2, the maximum relative displacement is $2.63 \mathrm{~mm}$ on R1 pier. Under both cases, the peak values of beam-rail relative displacement are less than $4 \mathrm{~mm}$.

It can be known that CWR on mid-span of main beam is the weakest location of tensile force under temperature dropping and bending loads. The rail head compressive stress is $282.14 \mathrm{MPa}$ and rail bottom tensile stress is 266.36 MPa, both of which are smaller than the permissible stress of $351.50 \mathrm{MPa}$. In addition, rail resultant force of basic thermal compressive force and rail bending force is $964.7 \mathrm{kN}$ which is smaller than the permissible force of $1505.10 \mathrm{kN}$.

Compared to the schemes without REJ, the rail longitudinal force gets reduced significantly. Even, in the cablestayed bridge, the strength and stability of CWR can confirm to the requirements. According to the calculations, it is found that the peak values of rail longitudinal force in two REJ paving schemes are almost the same.

4.2. Optimization of REJ Layout. Through rail longitudinal force under complex loads, the feasibility of two proposed schemes is determined. REJ layouts are optimized by the stock rail longitudinal force at the main beam joint, adjacent pier longitudinal force, and beam-rail relative displacement.

4.2.1. Rail Longitudinal Force at the Main Beam Joint. Figure 10(a) shows the stock rail longitudinal force of REJ at the beam joint when REJ paving locations are different 


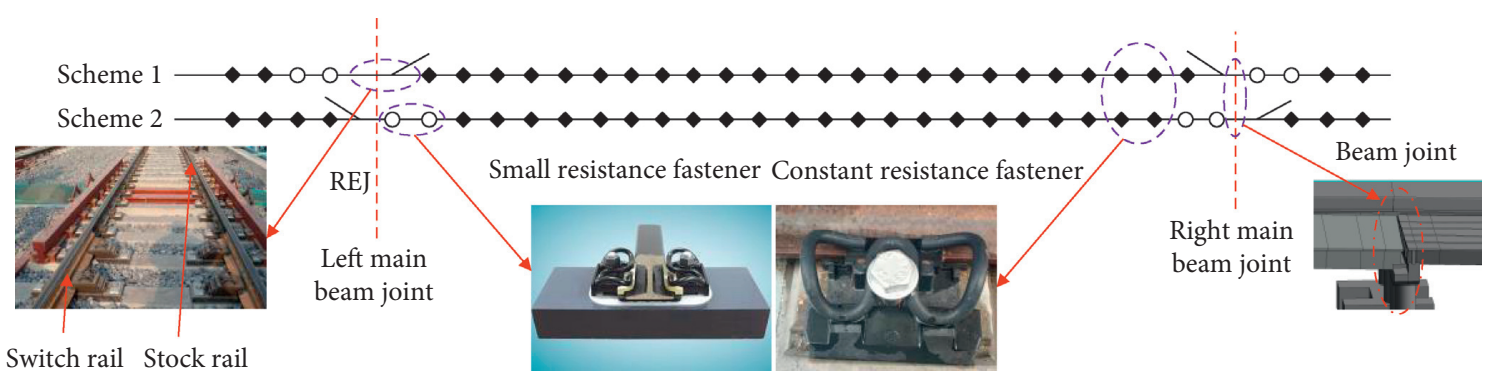

- Constant resistance fastener

- Small resistance fastener

$\measuredangle$ Rail expansion joint (REJ)

FIGURE 6: REJ paving schemes diagram.

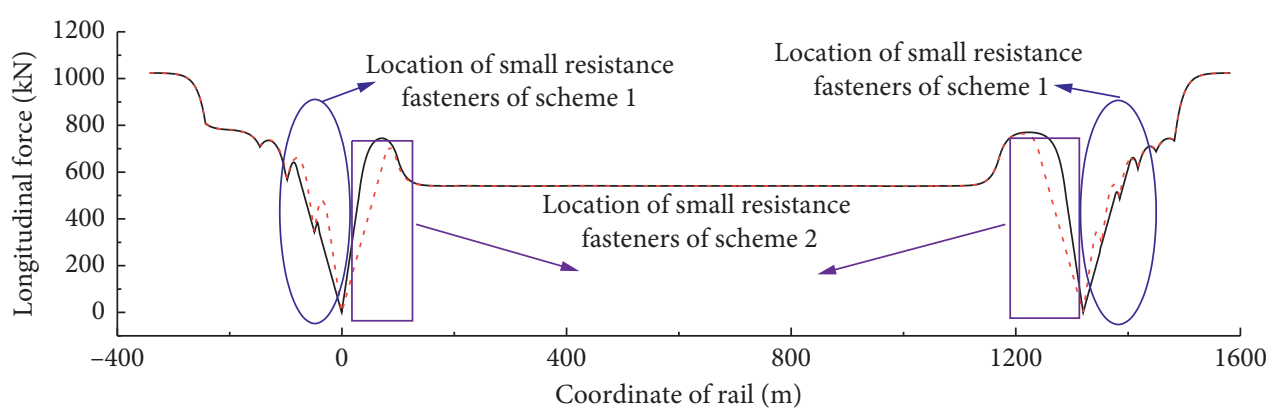

(a)

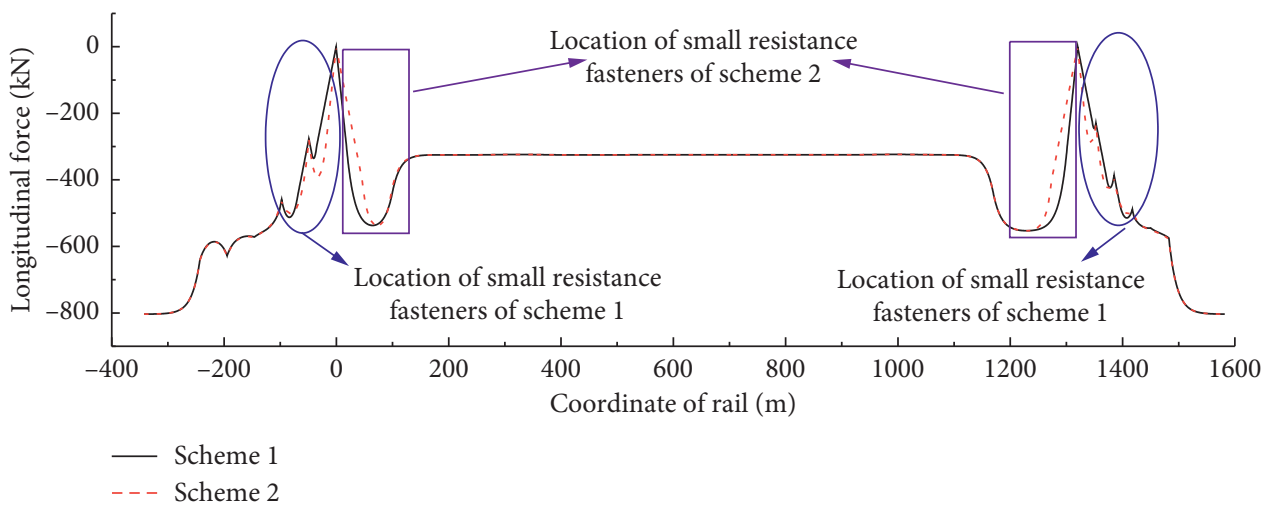

(b)

FIgURE 7: Rail longitudinal force under expansion condition. (a) Temperature dropping. (b) Temperature rise.

distances from the beam joint. It can be found that the further REJ is from the beam joint, the larger stock rail longitudinal force is. There is a linear relationship between the distance and stock rail longitudinal force. Stock rail longitudinal force is minimal with REJ located at the beam joint. In order to reduce stock rail longitudinal force, the stock rail should not be far away from the beam joint. The switch rail should be more than $2 \mathrm{~m}$ away from the beam joint to avoid the vibration.

4.2.2. Fixed Pier Longitudinal Force. The rail longitudinal force produced by temperature load will lead to the fixed pier longitudinal force and the pier longitudinal force of L5 and R5 which are considered in Figure 10(b). Under bending condition, the fixed pier longitudinal force of L5 is $3071.49 \mathrm{kN}$ and $5759.33 \mathrm{kN}$ in schemes 1 and 2, respectively, and that for $\mathrm{R} 5$ is $2047.74 \mathrm{kN}$ and $3839.61 \mathrm{kN}$. Compared with scheme 2, the pier longitudinal force of L5 and R5 in scheme 1 reduces by $46.69 \%$ and $46.67 \%$. When small resistance fasteners are laid on the simply supported beams, the bridge-track interaction can be alleviated; the fixed pier longitudinal force near the main beam reduces.

4.2.3. Beam-Rail Relative Displacement. In order to investigate the influence of the switch rail, stock rail, and small resistance fasteners on the beam-rail relative displacement, the braking loads are applied from $-242.5 \mathrm{~m}$ to $157.5 \mathrm{~m}$. As shown in Figure 11, the maximum beam-rail relative 


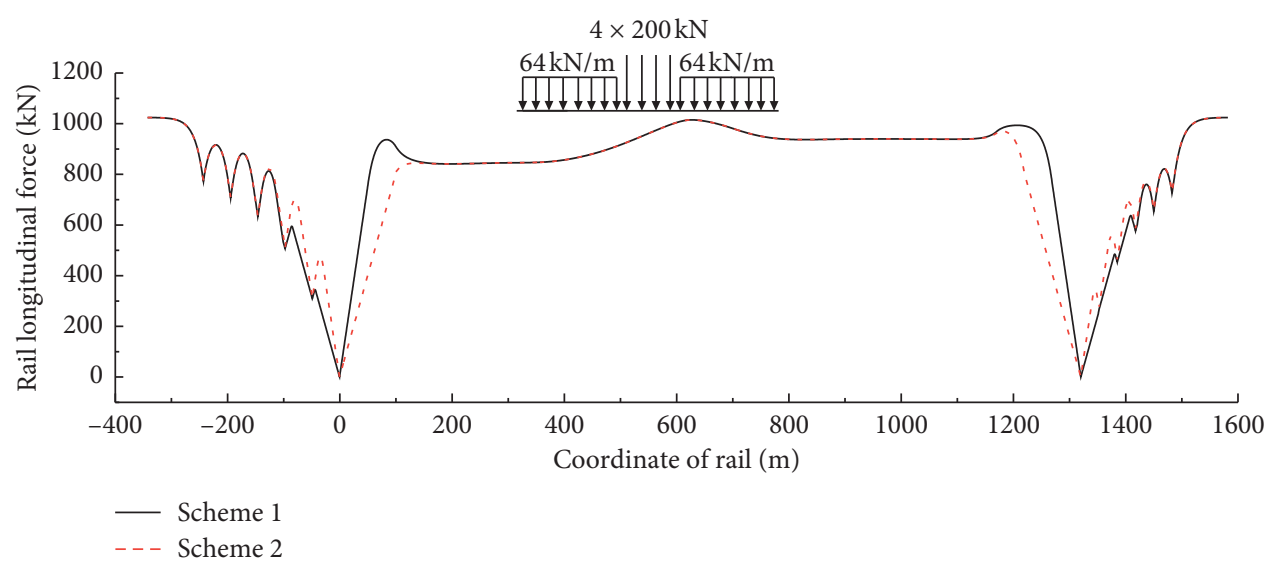

(a)

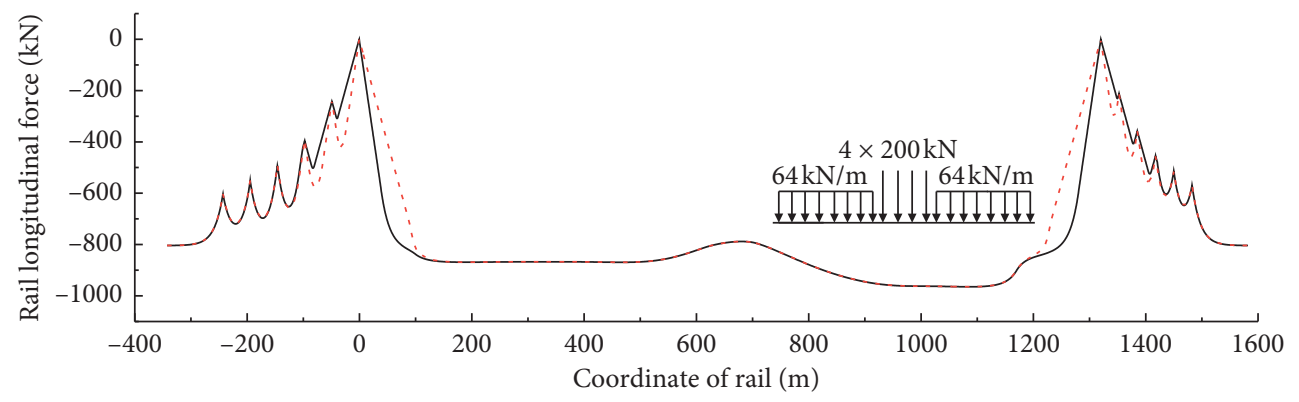

(b)

FIgURE 8: Rail longitudinal force under bending condition. (a) Temperature drop and bending loads. (b) Temperature rise and bending loads.

displacement in scheme 1 and scheme 2 are both $3.75 \mathrm{~mm}$, which locates at the first bridge abutment. The beam-rail relative displacement of the section laying small resistance fasteners is larger than that of the section laying constant resistance fasteners. Both peak values are less than the threshold of $30 \mathrm{~mm}$. The expansion of REJ under braking condition is $0.69 \mathrm{~mm}$.

For scheme 1, small resistance fasteners on approach bridges can reduce fixed pier longitudinal force near the main beam. The switch rails are laid on the main beam. The constant resistance fasteners are set up. It can increase the integrity of the structure and reduce the deflection of the steel box beam. It is also conducive to keep the ballast bed and track geometry in a good condition. The switch rails are located at the main beam; stock rails and small resistance fasteners are located at the simply supported beam approach bridges; scheme 1 is the better arrangement scheme of REJ.

4.3. Rail Gap Value under Braking Condition. The probability of two or more rails braking at the same time is very little, so only one rail braking is considered when calculating rail gap value of scheme1. Considering the most unfavorable condition, rail temperature reduces by $53.4^{\circ} \mathrm{C}$. Rail brakes on the middle of main beam (case 1 ) or the location of pier L1 (case
2). The rail longitudinal displacements are shown in Figure 12. The rail gap values under cases 1 and 2 are $43.61 \mathrm{~mm}$ and $37.88 \mathrm{~mm}$, respectively, which are less than $70.0 \mathrm{~mm}$; rail gap value can meet the requirement of code. The contractive displacements of REJs on the left and right beam end are $93.75 \mathrm{~mm}$ and $82.26 \mathrm{~mm}$, respectively.

4.4. Expansion Range of REJ. The expansion range of REJ is an important factor for choosing REJ. There are so many loads acting on the bridge. Factors that influence expansion amounts of REJ on long-span bridges are worth determining. The expansion amounts of REJs under different conditions of temperature, train, and seismic loads are shown in Figure 13.

The historical temperature differential is $69.3^{\circ} \mathrm{C}$ at the region where the bridge locates. Considering the most unfavorable conditions, temperature differential amplitude of main towers, stay cables, and beams is $34.65^{\circ} \mathrm{C}$. The rail dropping and rising temperature amplitudes are $53.4^{\circ} \mathrm{C}$ and $41.9^{\circ} \mathrm{C}$, respectively. The expansion amounts (Figure $13(\mathrm{a})$ ) for two sides of REJs are $330.39 \mathrm{~mm}$ and $316.27 \mathrm{~mm}$ under temperature dropping condition, respectively, and those for temperature rising condition are $310.63 \mathrm{~mm}$ and $298.34 \mathrm{~mm}$, respectively. Under four-line bending loads, the REJ 


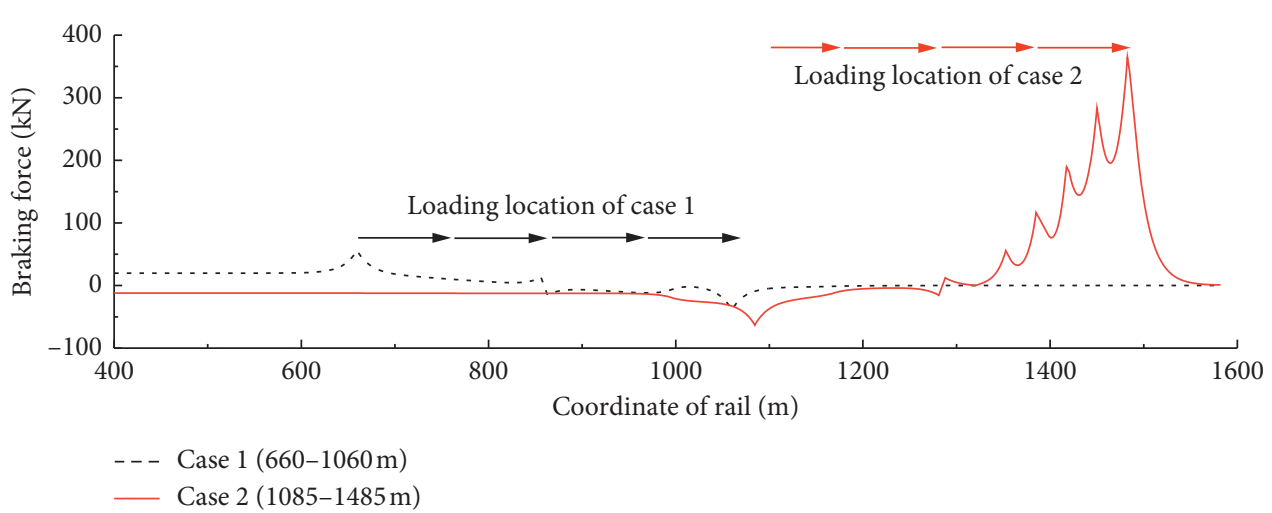

(a)

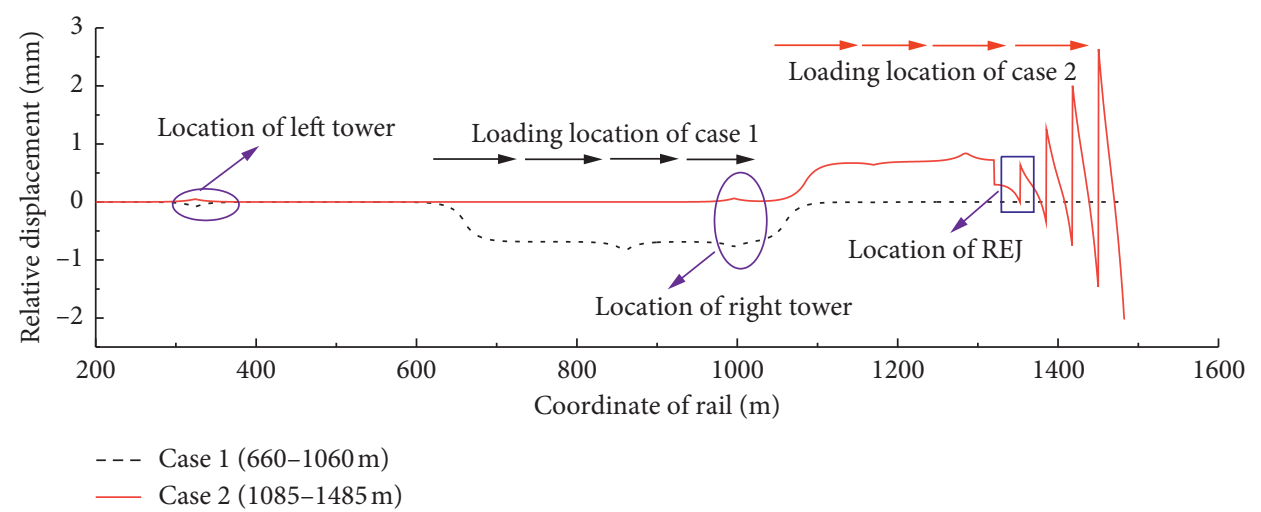

(b)

FIGURE 9: Braking and starting condition with REJs. (a) Rail braking force. (b) Beam-rail relative displacement.

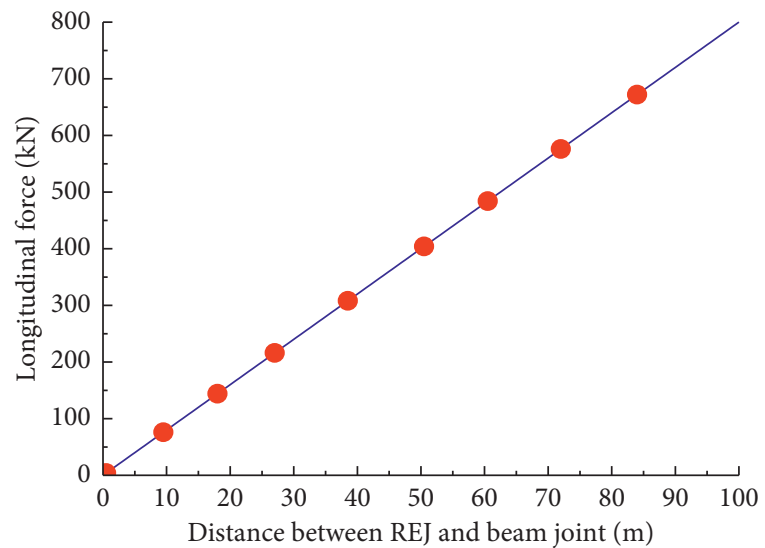

(a)

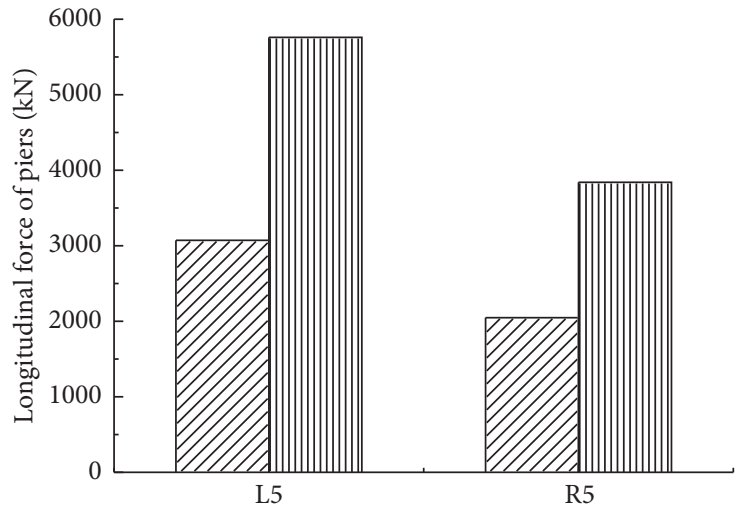

VIIIS Scheme 1

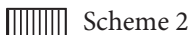

(b)

FIGURE 10: Rail longitudinal force and adjacent pier longitudinal force. (a) Rail longitudinal force at the end of the beam. (b) Adjacent pier longitudinal force.

expansion amount is $21.74 \mathrm{~mm}$. Due to the damping devices and the constraint of stay cables, the REJ expansion amount is even smaller under braking condition.

Considering traveling wave effect, the wave velocity is $2000 \mathrm{~m} / \mathrm{s}$; Ninghe Seismic Wave in Tianjin is applied to pile foundation of bridge with large-mass method. The expansion amounts (Figure 13(b)) of REJ on two sides are
$73.66 \mathrm{~mm}$ and $145.23 \mathrm{~mm}$, respectively. It can be found that REJ expansion amounts induced by rail braking and seismic loads are much smaller than those under temperature differentials.

It can be concluded that temperature, rail braking, and earthquake condition have a big impact on the expansion amount of REJ laid on cable-stayed bridge; the bending and 


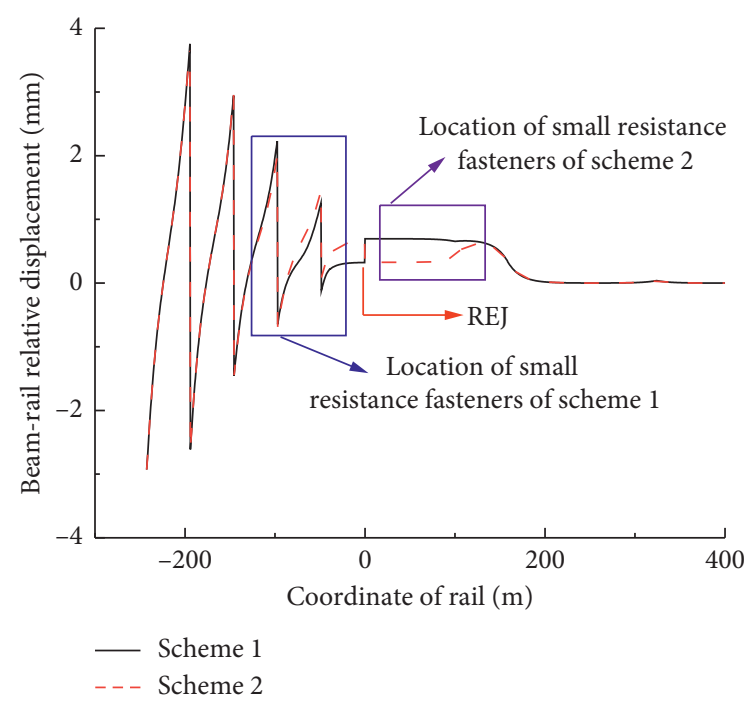

FIgURE 11: Beam-rail relative displacement.

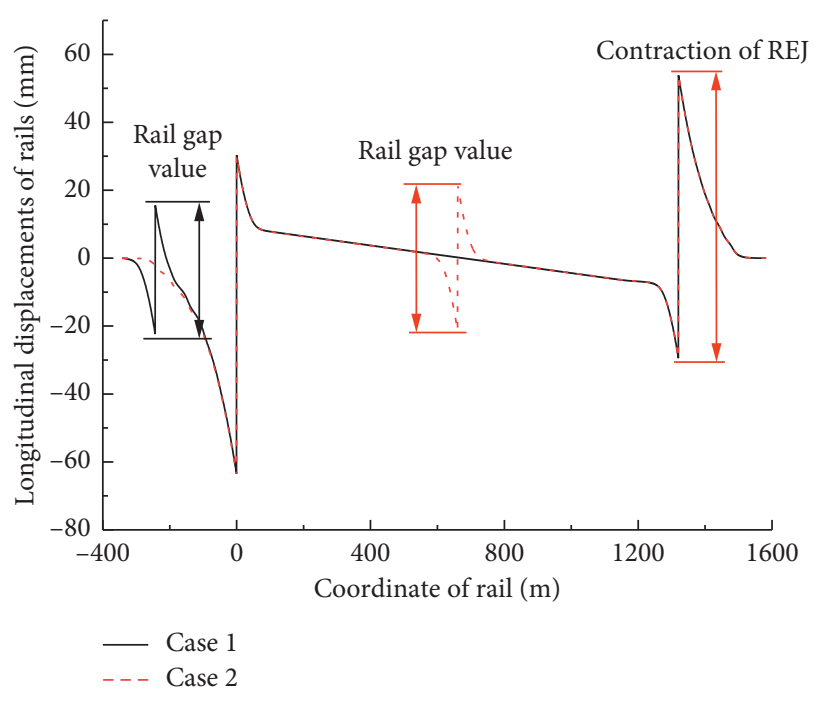

Figure 12: Rail longitudinal displacement.

braking loads have little effect on expansion range of REJ that can be ignored.

The probability of simultaneous action of four kinds of loads is very small, but the superposition effect of the expansion and the surplus of expansion should be considered to ensure the safety of high-speed railway. The recommended range of REJ on the newly built railway cable-stayed bridge can be $330.39+93.75+145.23=569.37 \mathrm{~mm}$ under the most disadvantageous conditions. Taking the range of the existing REJ production and the safety of CWR into account, it is suggested that the range of REJ is $\pm 600 \mathrm{~mm}$.

REJ with large expansion range should be used along with sleeper-supporting apparatus to dispose of uneven stiffness of track at the beam joints caused by the large displacement of main beam.

\section{Field Validation}

The bridge calculated previously is still under construction. In order to design the distribution of REJ along the bridge better, the monitoring data of REJ on Tongling Yangtze River cablestayed bridge which is similar to the new cable-stayed bridge is applied and analyzed thoroughly. The existing bridge is a steel truss cable-stayed bridge with twin towers and its main span is $645 \mathrm{~m}$. The design speed of the bridge is $250 \mathrm{~km} / \mathrm{h}$ and REJs are installed at the ends of the main beam. The predicted expansion displacements of REJ based on the monitoring data can be used as verification and reference for the design of REJ on the new cable-stayed bridge.

5.1. Monitoring Method. The sensors for the long-term monitoring of high-speed railway should be equipped with high security, high stability, corrosion resistance, anti-interference, and sufficient accuracy. Fiber Bragg Grating (FBG) technology and Image Intelligent Identification technology are used.

5.1.1. FBG Technology. FBG method has advantages of interference immunity and high precision, which can meet requirements of monitoring rail longitudinal force and temperature [36-38]. There is 1 point to measure environment temperature, and there are 4 points to measure the rail temperature in the range of REJ. Due to the special position of REJ, it is difficult to measure expansion amounts of REJ with FBG technology. However, Image Intelligent Identification technology is an ideal choice [39-41].

5.1.2. Image Intelligent Identification Technology. The images about the relative position of REJ structure and scale are obtained by cameras. Based on the Image Identification technology, the video camera is used to record the expansion displacement of REJ. Two monitoring points locate at the switch rail; one point locates at the stock rail for one set of REJ as shown in Figure 14. QR code is pasted on stock rail; the cloud corresponding to $\mathrm{QR}$ code can store monitoring information which can be obtained automatically by scanning QR code.

5.2. Monitoring Data Analysis and Discussion. The relationship between the expansion displacement of REJ at Tongling Yangtze River cable-stayed bridge and the environment temperature is shown in Figure 15(a). The trend of REJ expansion displacement is similar to environment temperature variation. To further reveal the relationship between the daily expansion displacement $(\mathrm{y} / \mathrm{mm})$ of REJ and the daily variation of environment temperature $\left(\mathrm{T} /{ }^{\circ} \mathrm{C}\right)$, the fitting and analysis of the monitoring data are carried out as shown in the red line in Figure 15(b). The relationship can be expressed as follows:

$$
y=8.638 \times T-2.856,
$$




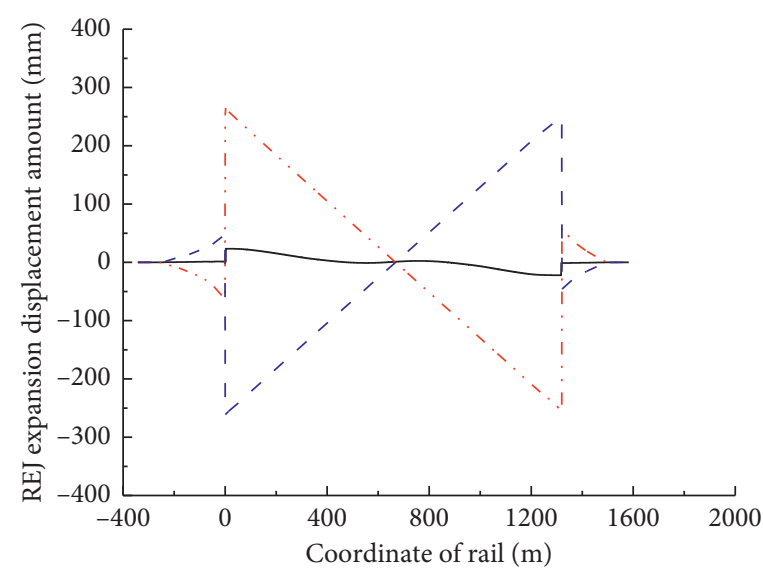

- Bending deformation

-.. Temperature drop

- - - Temperature rise

(a)

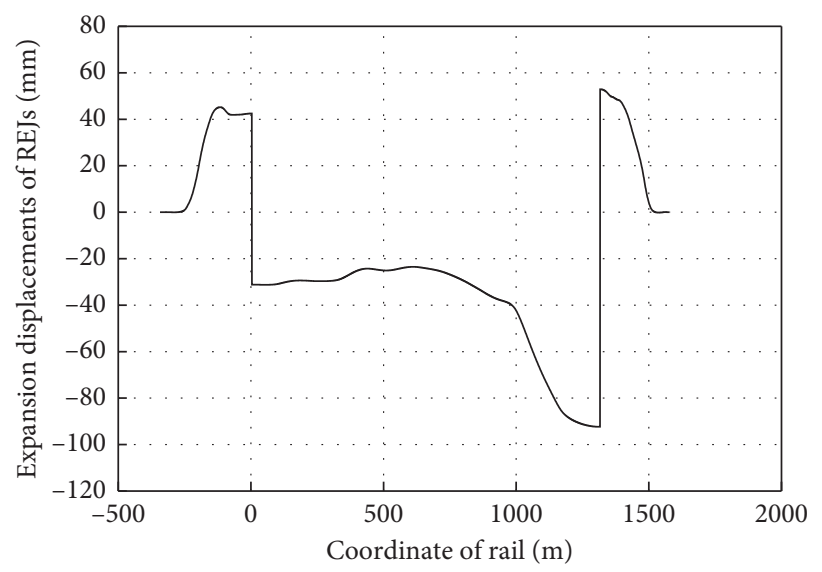

(b)

Figure 13: REJ expansion displacements. (a) Effect of temperature and bending conditions. (b) Effect of the seismic load.

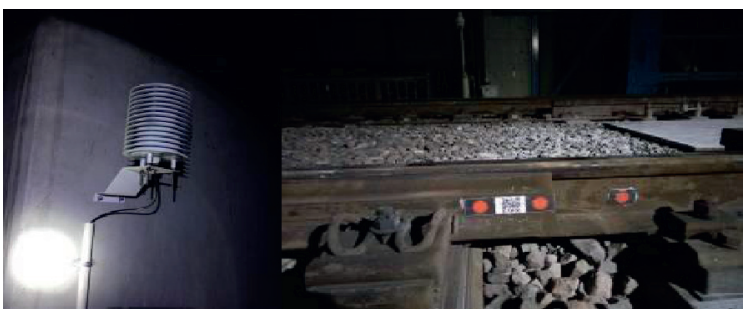

(a)
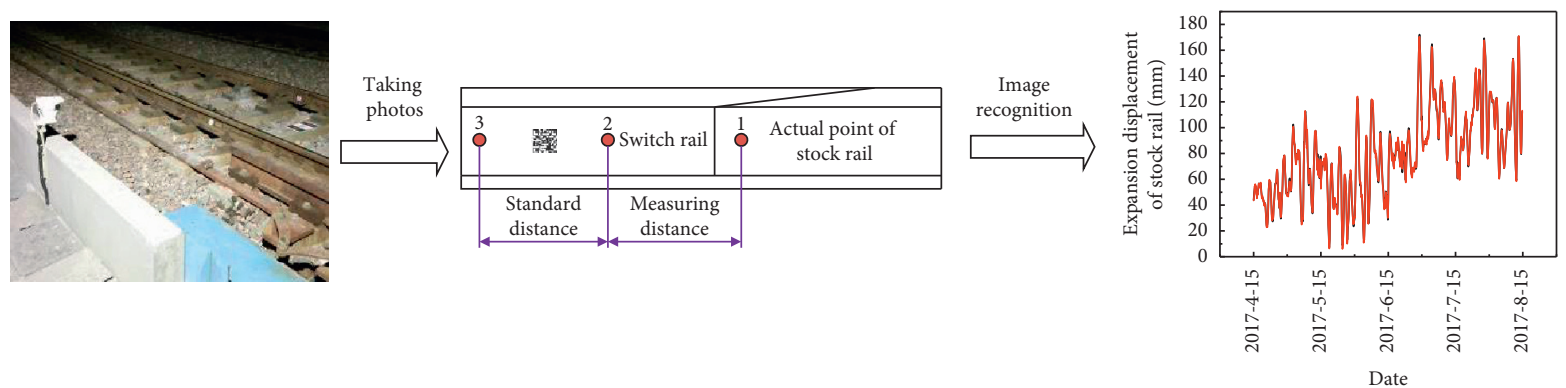

(b)

Figure 14: Measurement of Image Intelligent Identification technology. (a) Measurement point for the atmospheric temperature and displacement of the switch rail. (b) Monitoring method of the expansion displacement of REJ.

where $T$ is the environment temperature $\left({ }^{\circ} \mathrm{C}\right)$ and $y$ is REJ expansion displacement $(\mathrm{mm})$. The goodness of the formula fitting ( $R$-square) is 0.81 .

In view of the consistent bridge with similar span and surrounding environment of the Tongling bridge, the variation of REJ expansion displacement has a valuable reference for the cable-stayed bridge being designed. When temperature changes, the expansion of the main beam of cable-stayed bridge will lead to deformation of rail, which is linear with the expansion of main beam. It can be known from $\Delta l=\alpha \times l \times \Delta t$ that the expansion deformation of beam is linear with the length of main beam when temperature changes consistently. Since the structure type and the length of main beam of the bridge in this paper are similar to Tongling bridge, the variation of expansion displacement and daily environment temperature of the bridge in this paper can be deduced through the fitting curve by the monitoring data of REJ on Tongling bridge. The length of main beam of Tongling bridge and the bridge in this paper is $1290 \mathrm{~m}$ and $1320 \mathrm{~m}$, respectively, so the formula of expansion displacement and daily environment temperature of bridge in this paper can be deduced: 


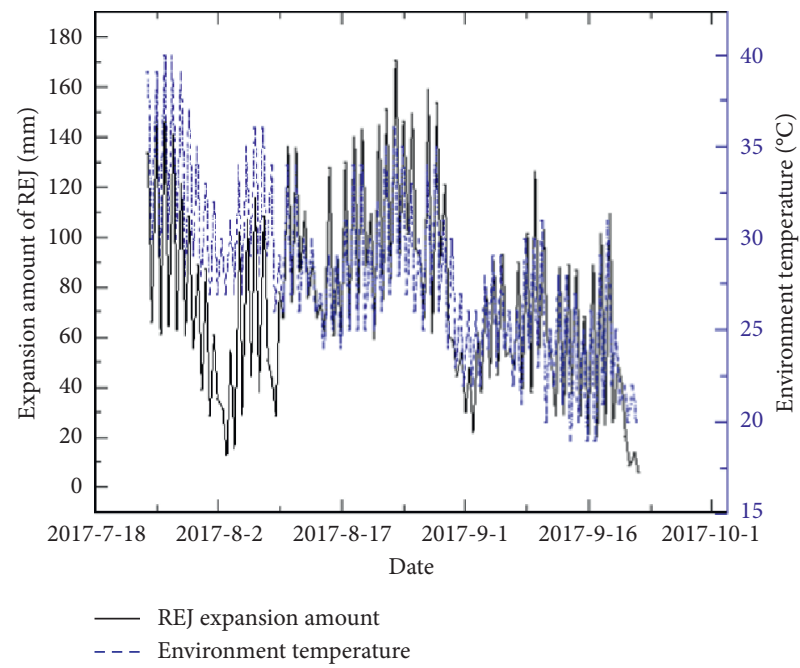

(a)

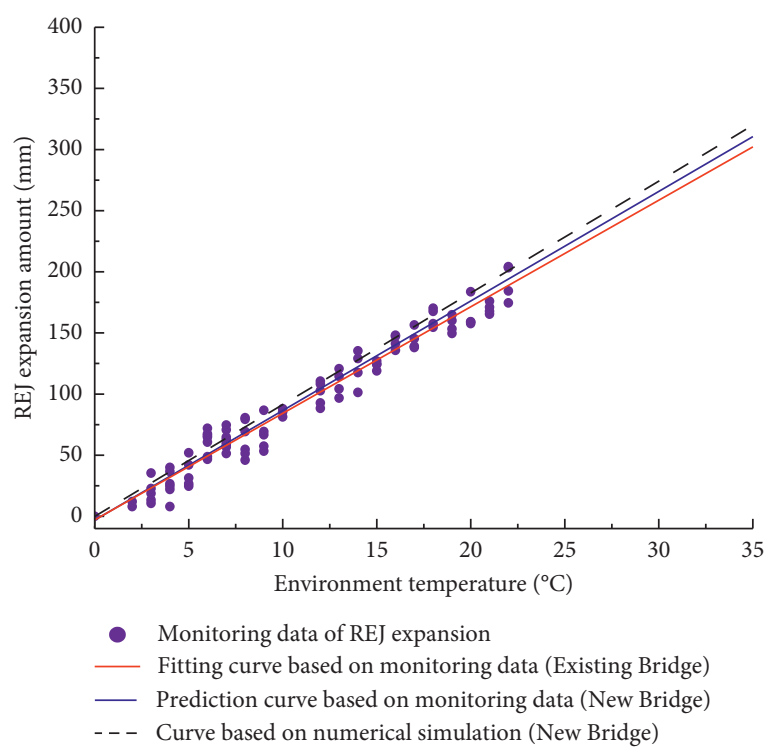

(b)

FIgURE 15: Relationship between REJ expansion and environment temperature. (a) REJ expansion during different periods. (b) Fitting curves.

$$
y=(8.638 \times T-2.856) \times \frac{1320}{1290}=8.839 \times T-2.922,
$$

as shown in the blue line in Figure 15(b). The relationship between the variation of the expansion displacement and the environment temperature differential is calculated by the numerical simulation model: $y=9.14 \times T$, as shown in the black line in Figure 15(b).

Predicted by the field monitoring data of the existing bridge, the maximum displacement of REJ on the new bridge is $304.5 \mathrm{~mm}$ under extreme temperature. The maximum displacement deduced by the numerical model is $316.7 \mathrm{~mm}$. The expansion displacement of REJ on the new cable-stayed bridge deduced from the fitted curve of the field monitoring data is basically consistent with the numerical simulation results. This means that the optimal scheme and expansion range of REJ proposed by the numerical simulation are feasible. Based on the field monitoring data, the established numerical model can predict the layout optimization of REJ on cable-stayed bridges.

\section{Conclusions}

The numerical coupling model of CWR on the long-span cable-stayed bridge is established by taking the influence of pile-soil interaction into account. Rail longitudinal force on cable-stayed bridge under different conditions is discussed. The layout optimization method of REJ on cable-stayed bridge is proposed. The numerical simulation is verified by comparing with the field monitoring data. The conclusions are drawn as follows:

(1) The longitudinal thermal stress of CWR on the long-span cable-stayed bridges plays a controlling role in strength and stability of CWR. The application of REJ is essential for CWR on the long-span cable-stayed bridge to reduce the rail longitudinal force effectively.

(2) From the perspective of technical and field conditions, the unidirectional REJ should be laid at both ends of the long-span cable-stayed bridge. Switch rail of REJ should be located at the main beam, stock rail should be set on the approach bridge and crossing over beam expansion joint, and several-meter small resistance fasteners should be laid on the side of stock rail to reduce fixed pier longitudinal force near the main beam.

(3) The expansion range of REJ laid on cable-stayed bridge is mainly decided by the variation of rail and bridge temperature, rail breaking, and earthquake loads; the bending and braking load have little influence on it so that the loads can be ignored.

(4) The monitoring data of REJ on Tongling Yangtze River can prove that the method to optimiazte the layout of REJ is effective. The method can be provided as reference for the layout of REJ on other cable-stayed bridges.

\section{Data Availability}

The monitoring data used to support the findings of this study are available from the corresponding author Yongjie Gao, who works at China Railway Siyuan Survey and Design Group Co., Ltd.

\section{Conflicts of Interest}

The authors declare that they have no conflicts of interest. 


\section{Acknowledgments}

This work was supported by the National Natural Science Foundation of China (no. 51778050), China National Key R\&D Plan (2016YFB1200100), and China Railway R\&D Project (no. P2018G047). Great appreciation is also given to all members of our research group for their assistance.

\section{References}

[1] P. Ruge and C. Birk, "Longitudinal forces in continuously welded rails on bridge decks due to nonlinear track-bridge interaction," Computers \& Structures, vol. 85, no. 7-8, pp. $458-475,2007$.

[2] C. B. Cai, "Calculation of additional longitudinal forces in continuous welded rails on supper-large bridges of high-speed railways," Journal of Southwest Jiaotong University, vol. 38, no. 5, pp. 609-614, 2003.

[3] M. P. Petrangeli, "The Italian experience: two case studies," in Proceedings of the Track-Bridge Interaction on High-Speed Railways: Selected and Revised Papers from the Workshop on Track-Bridge Interaction on High-Speed Railways, pp. 139148, Porto, Portugal, October, 2007.

[4] P. Ruge, D. R. Widarda, and L. Bagayoko, "Longitudinal track-bridge interaction due to sudden change of coupling interface," Computers \& Structures, vol. 87, no. 1-2, pp. 47-58, 2009.

[5] B. Yan, G. L. Dai, and H. P. Zhang, "Beam-track interaction of high-speed railway bridge with ballast track," Journal of Central South University of Technology, vol. 19, no. 5, pp. 1447-1453, 2012.

[6] Q. Y. Xu, X. F. Chen, and S. D. Li, "Study on the additional longitudinal forces transmission between continuous welded rails and high-speed railway bridges," China Railway Science, vol. 27, no. 3, pp. 8-12, 2006.

[7] H. Liu, P. Wang, X. Wei, J. Xiao, and R. Chen, "Longitudinal seismic response of continuously welded track on railway arch bridges," Applied Sciences, vol. 8, no. 5, p. 775, 2018.

[8] B. Yan, S. Liu, H. Pu, G. Dai, and X. Cai, "Elastic-plastic seismic response of CRTS II slab ballastless track system on high-speed railway bridges," Science China Technological Sciences, vol. 60, no. 6, pp. 865-871, 2017.

[9] M. K. Song, H. C. Noh, and C. K. Choi, "A new three-dimensional finite element analysis model of high-speed trainbridge interactions," Engineering Structures, vol. 25, no. 13, pp. 1611-1626, 2003.

[10] R. Joy, D. Otter, and D. Read, "CWR on steel bridges," Railway Track \& Structures, vol. 104, no. 8, pp. 17-20, 2008.

[11] R. Karoumi, "Some modeling aspects in the nonlinear finite element analysis of cable supported bridges," Computers \& Structures, vol. 71, no. 4, pp. 397-412, 1999.

[12] P. G. Papadopoulos, J. Arethas, P. Lazaridis, E. Mitsopoulou, and J. Tegos, "A simple method using a truss model for inplane nonlinear static analysis of a cable-stayed bridge with a plate deck section," Engineering Structures, vol. 30, no. 1, pp. 42-53, 2008.

[13] H. T. Thai and S. E. Kim, "Nonlinear static and dynamic analysis of cable structures," Finite Elements in Analysis and Design, vol. 47, no. 3, pp. 237-246, 2011.

[14] H. Xu, H. Liu, H. S. Lin, H. Yan, and P. Wang, "Influence factors analysis of expansion and contraction force of continuous welded rails on long-span cable-stayed bridge," Journal of Railway Engineering Society, vol. 32, no. 12, pp. 34-39, 2015.
[15] F. Benedettini and C. Gentile, "Operational modal testing and FE model tuning of a cable-stayed bridge," Engineering Structures, vol. 33, no. 6, pp. 2063-2073, 2011.

[16] J. Liu, W. L. Qu, and Y. L. Pi, “Active/robust control of longitudinal vibration response of floating-type cable-stayed bridge induced by train braking and vertical moving loads," Journal of Vibration and Control, vol. 16, no. 6, pp. 801-825, 2010.

[17] Y. Li, "Study on variation rules of longitudinal force of continuous welded rails on long-span cable-stayed bridge," Journal of Railway Engineering Society, vol. 29, no. 10, pp. 42-46, 2012.

[18] G. L. Dai and B. Yan, "Longitudinal forces of continuously welded track on high-speed railway cable-stayed bridge considering impact of adjacent bridges," Journal of Central South University, vol. 19, no. 8, pp. 2348-2353, 2012.

[19] P. Wang, H. Liu, X. K. Wei, and J. L. Xiao, "Analysis of longitudinal force regulation for CWR on railway cablestayed bridge," Journal of Traffic and Transportation Engineering, vol. 13, no. 5, pp. 27-32, 2013.

[20] P. Wang, W. H. Zhao, R. Chen, and J. L. Xiao, "Bridge-rail interaction for continuous welded rail on cable-stayed bridge due to temperature change," Advances in Structural Engineering, vol. 16, no. 8, pp. 1347-1354, 2013.

[21] W. H. Zhao, P. Wang, and Y. Cao, "Simplified algorithms for continuous welded rail design on large span steel truss cablestayed bridge," in Proceedings of the 1st International Workshop on High-Speed and Intercity Railways, pp. 173-178, Shenzhen, China, July 2012.

[22] K. Z. Xie, P. Wang, L. Wang, and R. Chen, "Impact of seismic effects on rail expansion joints on bridge," Journal of the China Railway Society, vol. 38, no. 3, pp. 111-118, 2016.

[23] J. H. Min, C. H. Lee, J. K. Ryu, and X. S. Jin, "Research about expansion joint of continuous welded rail on reset," in Proceedings of the KSR Conference, pp. 2129-2134, Seongnam, Korea, October 2011.

[24] H. U. Bae, T. K. Kang, K. J. Min, and N. H. Lim, "The effect of the tied sleeper on the maintenance work in the rail expansion joint zone," in Proceedings of the KSR Conference, pp. 21252128, Seongnam, Korea, October 2011.

[25] J. S. Chung and J. S. Lee, "Effects of bridge bearings by structure-track interaction for continuous bridge applied CWR with rail expansion joint under temperature load," Journal of the Korean Society of Safety, vol. 25, no. 5, pp. 54-61, 2010.

[26] R. Calçada, R. Delgado, A. C. e Matos, J. M. Goicolea, and F. Gabaldon, Track-bridge Interaction on High-Speed Railways: Selected and Revised Papers from the Workshop on Track-Bridge interaction on High-Speed Railways, CRC Press, Porto, Portugal, 2011.

[27] K. Z. Xie, W. G. Zhao, X. P. Cai, H. Liu, and H. Zhang, "Impacts of initial internal force and geometric nonlinearity of suspension bridge on bridge-rail interaction," Journal of Traffic and Transportation Engineering, vol. 20, no. 1, pp. 82-91, 2020.

[28] TB10093-2017, Code for Design on Subsoil and Foundation of Railway Bridge and Culvert, China Railway Publishing House, Beijing, China, 2017.

[29] TB10015-2012, Code for Design of Railway Continuous Welded Rail, China Railway Publishing House, Beijing, China, 2012.

[30] K. Z. Xie, W. G. Zhao, X. P. Cai, P. Wang, and J. Zhao, "Interaction between track and long-span cable-stayed bridge: recommendations for calculation," Mathematical Problems in Engineering, vol. 2020, Article ID 5463415, 14 pages, 2020. 
[31] TB10002-2017, Code for Design on Railway Bridge and Culvert, China Railway Publishing House, Beijing, China, 2017.

[32] L. Shi, D. J. Wu, and Q. Li, "Analysis on stress of track on bridge considering loading history and track-bridge interaction," Journal of the China Railway Society, vol. 38, no. 2, pp. 105-111, 2016.

[33] N. H. Lim, N. H. Park, and Y. J. Kang, "Stability of continuous welded rail track," Computers \& Structures, vol. 81, no. 22-23, pp. 2219-2236, 2003.

[34] N. H. Lim, S. Y. Han, T. H. Han, and Y. J. Kang, "Parametric study on stability of continuous welded rail track-ballast resistance and track irregularity," Steel Structures, vol. 8, no. 3, pp. 171-181, 2008.

[35] B. Wang, J. H. Xu, L. Wang, and P. Wang, "Research on stability strengthening scheme of continuous welded rail on bridge in the small radius curve section," Applied Mechanics and Materials, vol. 505-506, pp. 106-110, 2014.

[36] W. L. Li, X. S. Lu, J. Pang, C. Zhang, and J. X. Dai, "FBG monitoring technology on urban railway expansion device of elevated bridge," Journal of Wuhan University of Technology, vol. 35, no. 9, pp. 133-137, 2013.

[37] W. L. Li, Y. X. Zhang, Q. Wang et al., "Displacement monitor with FBG deforming ring and its application in high speed railway," in Proceedings of the OFS2012 22nd International Conference on Optical Fiber Sensors, vol. 8421, p. 8421AU, Beijing, China, October 2012.

[38] R. Falciai and C. Trono, "Curved elastic beam with opposed fiber-bragg gratings for measurement of large displacements with temperature compensation," IEEE Sensors Journal, vol. 5, no. 6, pp. 1310-1314, 2005.

[39] A. V. Miguel, C. G. Dorys, M. Jesus, and S. Thomas, "A novel laser and video based displacement transducer to monitor bridge deflections," Sensors, vol. 18, no. 4, p. 970, 2018.

[40] S. Acikgoz, M. J. DeJong, and K. Soga, "Sensing dynamic displacements in masonry rail bridges using 2D digital image correlation," Structural Control and Health Monitoring, vol. 25, no. 8, p. e2187, 2018.

[41] L. Luo, M. Q. Feng, and Z. Y. Wu, "Robust vision sensor for multi-point displacement monitoring of bridges in the field," Engineering Structures, vol. 163, pp. 255-266, 2018. 